\title{
Psychiatry for the person and its ethical perspectives
}

Every medical (and psychiatric) act is or should be an ethical act. This is consistent with the fundamental aspirations of the medical and health field, from Hippocratic and similar ancient philosophical perspectives to recent developments in public and clinical policies. Ethical concerns have been priority institutional commitments since the beginnings of the World Psychiatric Association (WPA). In line with the above, the WPA established in 2005 an Institutional Program on Psychiatry for the Person. This editorial summarises the precedents, goals, structure and activities of this WPA initiative and outlines some of its ethical perspectives.

\section{The WPA Institutional Program on Psychiatry for the Person}

The need for holism in medicine was strongly advocated by Ancient Greek philosophers and physicians, the ethicists of those times. Socrates and Plato taught that 'if the whole is not well it is impossible for the part to be well', and such was also the position of Aristotle.'
These ideas are re-emerging today, not only within the Western medical tradition but also in a number of other rich traditions around the world. For example, Ayurvedic and Chinese medical traditions, ancient and still practised, with sound philosophical, experiential and experimental bases, focus on the patient's total health rather than only on disease. Both of them articulate a comprehensive and harmonious framework of health and life and promote a highly personalised approach for the treatment of specific diseases and the enhancement of quality of life. ${ }^{2}$

Concern for the centrality of the person is also being adopted by influential international health organisations through recent major statements by the US Presidential Commission on Mental Health and the WHO European Ministerial Conference on Mental Health. ${ }^{3,4}$

Another trend towards personalised medicine has emerged with the introduction of the concepts of recovery and resilience and of values-based medicine. ${ }^{58}$ These concepts support the involvement, active participation and responsibility of the person in protecting him- or herself from illness, promoting and maintaining health, and recovering from illness. 
The above considerations indicate the high relevance of a comprehensive understanding of health and the centrality of the person in such understanding and for the planning of health actions. In line with this, the 2005 General Assembly of the WPA established the Institutional Program on Psychiatry for the Person: from Clinical Care to Public Health (IPPP). This initiative affirms the whole person of the patient in context as the centre and goal of clinical care and health promotion, at both individual and community levels. This involves the articulation of science and humanism to optimise attention to the ill and positive health aspects of the person. As care is basically a partnership experience, the programme involves the integration of all relevant health and social services. Furthermore it involves advancing propitious public health policies.

The programme goals can be summarised as the promotion of a psychiatry of the person lof the totality of the person's health, both ill and positive), by the person (with clinicians adopting humanistic and ethical attitudes and extending themselves as full human beings), for the person lassisting the fulfilment of the person's life project), and with the person (in respectful collaboration with the person who consults). Operationally, the programme has four components, i.e. conceptual bases, clinical diagnosis, clinical care, and public health. ${ }^{9}$ Some of its ethical perspectives are outlined below.

\section{Ethical perspectives from a psychiatry for the person}

The context of each person is closely linked to identity. Nobody lives in a vacuum. This is exemplified by the philosopher Ortega y Gasset's dictum, 'I am I and my circumstance'. Clearly, a different, more comprehensive, more humanistic, more holistic and more person-centred perspective is needed..$^{10-14}$ Additionally, a more person-centred approach on the part of the physician is strongly encouraged. 15,16 This touches on ethics of the medical profession. Indeed, consideration of the patient as a person and not as a carrier of illness is a fundamental ethical obligation of the physician. This is consistent with the 'respect for autonomy' in principle-based ethics, ${ }^{17}$ and with each of the wide range of other ethical theories that support health care practice.

Consistent with a fundamental institutional concern present since its inception, the WPA approved in 1977 the Declaration of Hawaii, which set out ethical guidelines for the practice of psychiatry. This Declaration was updated in Vienna in 1983, Madrid in 1996, Hamburg in 1999, Yohohama in 2002 and Cairo in 2005, to reflect the impact of changing social attitudes and new medical developments on the psychiatric profession.

In its preamble, the Madrid Declaration (www.wpanet.org/about us/manual of procedures/appendix D) points out that medicine is both a healing art and a science, consistent with the IPPP emphasis on articulating science and humanism. The Declaration also indicates that ethical practice is based on the psychiatrist's individual sense of responsibility and that it should be guided primarily by the respect for patients and concern for their welfare and integrity.

Among its core guidelines, the Declaration points out that psychiatrists should devise therapeutic interventions that are least restrictive to the freedom of the patient, and that the patient should be accepted as a partner by right in the therapeutic process. The Declaration's additional guidelines include that the treatment approach should be determined in concert by the doctor and patient and/or the patient's family, that professional independence to apply best practice guidelines and clinical wisdom in upholding the welfare of the patient should be the primary considerations of the psychiatrist, and that the psychiatrist's respect for the humanity and dignity of the patient builds a foundation of trust that is essential for a comprehensive treatment plan.

Another important medical code of ethics is that issued by the World Medical Association (WMA) since 1964 and amended periodically as its Declaration of Helsinki on Ethical Principles for Medical Research Involving Human Subjects (www.wma.net). Tellingly, among other things it proclaims that in medical research on human subjects, considerations related to the well-being of the human subject should take precedence over the interests of science and society. The WPA has been invited this year by the WMA for the first time to participate formally in the review of the Helsinki Declaration, which opens opportunities for extending to the medical field at large WPA's ethical aspirations, including those that are particularly person-centred.

It is also worth noting that one of the major objectives of the IPPP is to promote a psychiatry with the person. It involves engaging the patient as a whole person and the commitment to work in a respectful and collaborative way with him or her. This includes firstly work with individuals, which highlights the ethical underpinnings of this effort. It also encompasses work with patient groups including those critical of psychiatry. These considerations speak clearly of the dialogal bases of our profession. ${ }^{18} \mathrm{~A}$ renewed commitment to the clinician-patient relationship appears crucial, as well as building an effective dialogue with patient and user groups (as well as trialogues including families) respecting the diversity of their perspectives. It should be noted that evolving evidence- and experience-based information in our field should also frame our professional work and interactions with patients.

\section{Concluding remarks}

Ethics have been a primary concern of major organisations such as the WPA and the WMA. They also stand at the core of the 


\section{editorials}

IPPP, which is attempting a paradigmatic shift to refocus our field on its fundamental soul.

\section{Juan E Mezzich}

President, WPA

Chair, WPA IPPP

Professor of Psychiatry and Director, International Center for Mental Health

Mount Sinai School of Medicine

New York University

\section{George Christodoulou}

President, Hellenic Center of Mental Health and Research

Chair, WPA Standing Committee on Ethics

Chair, WPA IPPP Conceptual Component

Professor of Psychiatry, National and Kapodistrian University

Athens, Greece

1. Christodoulou GN, ed. Psychosomatic Medicine. New York: Plenum Press, 1987

2. Patwardhan B, Warude D, Pushpangadan P, Bhatt N. Ayurveda and traditional

Chinese medicine: a comparative overview. Evidence-based Complementary and Alternative Medicine 2005; 2: 465-473.
3. US Presidential Commission on Mental Health. Achieving the Promise: Transforming Mental Health Care in America. Final Report. DHHS Pub N: SMA-03-3832. Rockville, Md: US Optimal Health and Human Services, 2003.

4. WHO European Ministerial Conference on Mental Health. Mental Health Action Plan for Europe: Facing the Challenges, Building Solutions. Helsinki, Finland, 12-15 January 2005. EUR/04/5047810/7

5. Anthony W. Recovery from illness. The guiding vision of the mental health service systems in the 1990s. Psychosocial Rehabilitation Journal 1993; 16: 11-23.

6. Amering M, Schmolke M. Recovery - Das Ende der Unheilbarkeit. Bonn: PsychiatrieVerlag, 2007.

7. Allott P, Loganathan L, Fulford KWM. Discovering hope for recovery. In: Innovation in Community Mental Health: International Perspectives. Canadian Journal of Community Mental Health 2002; 21 : Special Issue, 13-33

8. Fulford KWM, Thornton T, Graham G. Values, Ethics and Mental Health. Part IV of Fulford KWM, Thornton T, Graham G. The Oxford Textbook of Philosophy and Psychiatry. Oxford: Oxford University Press, 2006

9. Mezzich JE. Psychiatry for the person: Articulating medicine's science and humanism. World Psychiatry 2007; 6: 1-3

10. Antonovsky A. Unraveling the Mystery of Health. San Francisco: Jossey-Bass, 1987

1 1. Ricoeur P. Time and Narrative. Chicago, Ill.: University of Chicago Press, 1990.

12. Sensky T. Patients' reactions to illness. BMJ 1990; 300: 622-623.

13. Cloninger CR. Feeling Good: The Science of Well-Being. New York: Oxford University Press, 2004.

14. Mezzich JE. Positive health: Conceptual place, dimensions and implications. Psychopathology 2005; 38 (4): 177-179.

15. Cox J, Campbell AV, Fulford KWM, eds. Medicine of the Person: Faith, Science and Values in Health Care Provision. London: Jessica Kingsley Publishers, 2006.

16. UK Department of Health. Creating a Patient-led NHS: Delivering the NHS Improvement Plan. London: Department of Health, 2005.

17. Beauchamp T, Childress J. Principles of Biomedical Ethics. 4th ed. Oxford: Oxford University Press, 1994.

18. Mezzich JE. The dialogal bases of our profession: Psychiatry with the person. World Psychiatry (in press). 